\title{
Acculturative Stress and Disengagement: Learning from the Adjustment Challenges Faced by East Asian International Graduate Students
}

\author{
Dr. D. E. Lyken-Segosebe ${ }^{1}$ \\ ${ }^{1}$ Department of Business, Management, and Entrepreneurship, Botswana International University of Science and \\ Technology, Private Bag 16, Palapye, Botswana. \\ Correspondence: Dr. D. E. Lyken-Segosebe, Department of Business, Management, and Entrepreneurship, Botswana \\ International University of Science and Technology, Private Bag 16, Palapye, Botswana.
}

Received: October 16, 2017

Accepted: November 20, 2017

Online Published: November 24, 2017

doi:10.5430/ijhe.v6n6p66

URL: https://doi.org/10.5430/ijhe.v6n6p66

\begin{abstract}
International graduate students meet TOEFL, GPA, and other admissions criteria to gain entry into US colleges and universities. During their stay in the USA, they provide educational and economic contributions for their host country. In contrast to their educational and economic potential, international students often demonstrate poor academic and social integration at their host institutions. Grounded theory methodology was used to investigate what accounts for the academic, cultural, and social adjustment problems faced by East Asian graduate students pursuing studies at an elite private not-for-profit university in the USA. Findings reveal that students experienced lowered self-confidence and acculturative stress as a result of challenges encountered during their first year, language barriers, different teaching styles and teaching environments, and their interactions with professors. Raising faculty sensitivity to cultural differences among international students, early adjustment counseling and obtaining regular feedback are recommended.
\end{abstract}

Keywords: College student experience, Student engagement, International students, Adjustment, Acculturative stress

\section{Introduction}

Within higher education, student engagement is recognized as "key to enhancing students' college success" (Kuh, Kinzie, Schuh, Whitt, and Associates, 2010). High levels of learning, academic achievement, satisfaction with the college experience, persistence, and graduation are just some of the markers of student success attributed to engagement. These markers accrue by virtue of both the amount of time and effort students put into their studies and other activities that lead to student success; as well as by how the institution organizes learning opportunities and services to induce students to participate in and benefit from such activities (Kuh et al., 2010).

Student engagement is therefore both student-driven and institution-driven. However, before an institution can engage its students, it must understand these students, their needs and problems. This is particularly true for international students on US campuses. International graduate students meet TOEFL, GPA, and other admissions criteria to gain entry into US colleges and universities. In recent years, international student enrollment has been steadily increasing to the extent that international students now represent over five percent of the more than 20 million students enrolled in U.S. higher education (Institute of International Education, 2016). In the 2015/16 academic year, there were 1,043,839 international students attending these institutions, of which 383,935 (36.8\%) were graduate students. The top ten countries of origin for these students are China, India, Saudi Arabia, South Korea, Canada, Vietnam, Taiwan, Brazil, Japan, and Mexico. Indeed, China provided as much as $31.5 \%$ of all international students (328,547 students) in the 2015/16 academic year (Institute of International Education, 2016).

During their stay in the USA, international students create an impact both economically and educationally for their host country. They contribute more than $\$ 35$ billion to the U.S. economy, through spending on tuition and living expenses, including room and board, books and supplies, transportation, health insurance, and support for accompanying family members. Their economic impact is also made in terms of tax payments and US exports in the form of US-trained foreign professionals (Institute of International Education, 2016). These economic benefits are complemented by educational benefits because international students may bring cultural diversity to a campus, a diversity of viewpoints to the classroom, and an international or comparative focus to learning (de Araujo, 2011; Goodman, 1996; Wang, 2011; Winkler, 1984; Zhai, 2004). 
Despite their educational and economic potential, international students often demonstrate poor academic and social integration at their host institutions. They often encounter adjustment problems above and beyond the typical difficulties associated with college life (Boyer and Sedlacek, 1986; Mori, 2000; Wang, 2011). Adjustment represents "a transitional process that unfolds over time as students learn to cope with the exigencies of the university environment" (Al-Sharideh and Goe, 1998, p. 701). While the typical student may face institutional, academic, and personal emotional challenges from a new college environment, international students may face additional challenges in terms of social, linguistic, and cultural challenges from their geographical relocation (Yuan, 2010).

This study examines adjustment problems faced by international graduate students at a US university. The focus will be on a particular sample of international students - East Asian Master's and Ph.D. students pursuing graduate studies at an elite private not-for-profit doctoral university in the highest research activity category. Cross-cultural research suggests that international students from collectivist cultural backgrounds, such as East Asians, may experience lower levels of life satisfaction and higher levels of anxiety than international students from individualist cultures (Wang, 2011). Research studies (Barratt and Huba, 1994; Yeh and Inose, 2003) indicate that the geographical region from which an international student originates may influence how that student adjusts to campus life in the USA. Asian students may encounter more adjustment problems than European students (Yuan, 2010) and experience greater levels of stress than other international students due to language and cultural factors (Wilton and Constantine, 2003).

The research question guiding this inquiry is: Why do East Asian international graduate students experience problems adjusting to academic life in the United States? The study is significant for at least two reasons. First, little is known about the graduate student experience. The undergraduate experience dominates the literature. Second, a student's academic and social engagement can have a positive effect on student success and persistence. With the increasing numbers of international students coming to the USA to pursue an educational goal, it is not only important that colleges and universities provide special services to help these students adjust to the host culture and solve their unique problems (Boyer and Sedlacek, 1986; Zhai, 2004) but also individual departments within these institutions should be aware of the impact they have on student adjustment and contributions they can make at their level. According to Wan et al. (1992), by gathering and evaluating this information, educators will be better able to counsel individuals experiencing such stress, to take institutional actions to help alleviate the sources of the stress, and to prepare incoming international students to better handle the pressures they are likely to encounter (Zhai, 2004). International student retention can be at risk for departments and institutions that do not consider the problems and needs of international graduate students or provide help.

\section{Literature Review}

The extant literature indicates that international students generally tend to experience a magnification of common student problems coming to the American campus. These problems relate to their initial transition, academic life, social life, and psychological experiences.

\subsection{Initial Transition}

On arrival into the USA, international students need to find a place to live, get a social security number, and get a driver's license, and learn how to use public transportation. Married students need to find a school for their children or help their spouse find a job (Poyrazli and Grahame, 2007). They experience greater adjustment difficulties and more distress than their fellow incoming American students during this initial transition into the university and report greater academic and career needs (Hechanova-Alampay, Beehr, Christiansen, and Van Horn, 2002; Leong and Sedlacek, 1989; Van Oudenhoven and Van der Zee, 2002).

\subsection{Academic Life}

Academic problems encountered by international students during their adjustment process include the English language barrier, getting used to teaching and curriculum differences, and developing relationships with advisors and professors (Poyrazli and Grahame, 2007).

\subsubsection{English language barrier}

Limited English language proficiency may compromise international students' academic performance, and academic difficulties, in turn, may affect their psychological adjustment (Lin and Yi, 1997; Pedersen, 1991). Specifically with regard to Asian international students, Swagler and Ellis (2003) found that apprehension about speaking English affects the adjustment of Taiwanese students in particular, while Perkins, Perkins, Guglielmino, and Reiff (1977) found that as compared to Indian and other international students, Chinese students perceive English proficiency to be among the more serious problems. 
Why is communication difficult for these students? According to Wang (2003), cultures differ from each other in how much they rely on verbal messages to convey meaning. The author cites Hall (1976) who demonstrated how linguistic codes (words, phrases, and sentences) and contexts (background, preprogrammed responses of the recipient, and situations) are used together to convey meaning. Hall distinguished between high-context and low-context communication. In high-context communication "most of the information is either in the physical context or internalized in the person" (Hall, p.79). On the other hand, low-context communication of information relies more on explicit linguistic codes. American culture belongs to low-context culture while Chinese culture belongs to high-context culture. International students coming from high-context cultures may sometimes feel they are not understood in the low-context culture of the U.S. because they are not used to saying everything explicitly (Wang, 2003).

In addition, Sandhu and Asrabadi (1994) notes that difficulties may also arise when international apply different accents, enunciation, slangs, and use of special English words (Zhai, 2004). International students may not be familiar with how English is spoken and use their mother-tongue habit when they speak English, which may cause confusion. The wrong rhythm of speaking English can easily cause difficulty in understanding, and in turn difficulty in communication. International students who are accustomed to taking longer pauses between sentences may be cut short before they finish what they are saying (Wang, 2003).

\subsubsection{Curriculum and teaching procedures}

US curriculum and teaching procedures may hinder academic adjustment for international students. These procedures encompass study techniques, test taking, classroom instruction, and oral communication such as class discussion (White, Brown, and Suddick, 1983). Class participation is particularly stressful for East Asian international students since they originate from collectivist cultures. International students from a collective culture may not be trained to actively participate in classroom activities under the idea of avoiding open confrontation (Wang, 2003). For some international students, their limited classroom participation is attributed to a lack of personal assertiveness which is highly valued in the American classroom (Cigularova, 2005). Athen (1991) found that lack of assertiveness is more prevalent among Asian females.

\subsubsection{Relationships with advisors and professors}

Interaction between faculty members and international students may be negatively affected by divergent expectations of each other, and cultural understandings of power distance. When McCargar studied ESL students from different geographic regions that included the East Asia, the researcher found that students from this region expected their professors to act as authority figures (Wang, 2003). International students may have different understandings of power distance. Power distance is defined as "the extent to which the less powerful members of institutions and organizations accept that power is distributed unequally" (Hofstede and Bond, 1984, p. 419). In countries with "far" power distance (such as Asian countries), more respect is shown to professors. This power distance often prevents international students from approaching professors for help (Wang, 2003).

\subsection{Social Life}

International students face the challenge of making new friends, coping with loss of social support, and developing a new social support system (Poyrazli and Grahame, 2007). While students from a more individualistic culture may identify with the U.S. mainstream culture, others from a more collectivist culture may feel distant (Swagler and Ellis, 2003). Asian students express that their lack of familiarity with American social norms and customs make it difficult to make American friends and establish a social support network (Mori, 2000). Redmond and Bunyi (1993) found that British, other European, and South American students were more able to initiate interactions and maintain interpersonal relations with U.S. host students than Korean, Taiwanese, and Southeast Asian students (Cigularova, 2005).

\subsection{Psychological Experiences}

Psychological experiences include phenomena such as homesickness, disorientation, depressive reactions, and feelings of isolation, alienation, and powerlessness (Day and Hajj, 1986). International students from collectivist cultural backgrounds may experience lower levels of life satisfaction and higher levels of anxiety than students from individualist cultures (Sam, 2001; Surdam and Collins, 1984). This disparity may be due to the fact that when greater levels of cultural dissimilarity exist between two cultures, international students experience higher levels of adjustment stress (Yang and Clum, 1994; Surdam and Collins, 1984). 


\section{Method}

This study investigated the adjustment problems experienced by East Asian international graduate students who were pursuing studies at an elite US private not-for-profit university, classified as an R1doctoral university - highest research activity. The research literature indicates that East Asian students tend not to be very vocal about academic issues for cultural reasons. Grounded theory methodology provided the analytical strategy because the aim was to generate a theory from the perspectives of these students. Grounded theory methodology provides "systematic inductive guidelines for collecting and analyzing data to build middle-range theoretical frameworks that explain the collected data" (Charmaz, 2000, p. 509). The methodology provided access, through their own voices, to the perceptions of the affected students and their particular interpretations of their US and campus experiences so that a theory could evolve.

\subsection{Procedures}

\subsubsection{Sampling and Participants}

The study employed purposive sampling. Rubin and Rubin (1995) suggest three guidelines for selecting informants when using the purposive method. Informants should be: 1) knowledgeable about the cultural area or situation or experience being studied, 2) willing to talk, and 3) representative of the range of points of view. The study sample comprised seven East Asian international graduate students (two Chinese, three Koreans, one Taiwanese, and one Japanese). They were selected for three reasons. First, these participants originated from within the top ten countries of origin for international students entering the USA. Second, they were representative of East Asia, the geographic region from which the department under study attracted the most international students. Third, the research literature indicated that these students tend to have higher levels of adjustment problems to US campus life.

\subsubsection{In-Depth Interviews}

The data for this study was collected from individual student interviews. For better control of reliability in the questioning process, all interviews were personally conducted by the study researcher. An interview protocol was designed that contained a set of core questions related to the academic, academic, cultural, and social adjustment issues experienced by international students, their coping strategies, and perceptions about what the faculty and the department should do to help them adjust. Interviews ranged from 30 minutes to one hour each. After participants gave informed consent, interviews were digitally recorded and later transcribed. Field notes made as an additional source of detail. Methodological, theoretical, and personal notes were added after each interview to record further insights into the interview and associated research questions. Participants were assigned pseudonyms to protect their identity. Table 1 shows the countries of origin and academic profiles of the seven students who participated in this study. The three students in the Master's program were in their second year of study. Of the four PhD students, one was in the second year, two were in their third year, and one was in the fifth year.

Table 1. Country of Origin and Degree Pursued by Participants

\begin{tabular}{lll}
\hline Pseudonym & Country & Program \\
\hline Anna & China & Master's \\
Lydia & Korea & PhD \\
Paul & Taiwan & Master's \\
Peter & Japan & $\mathrm{PhD}$ \\
Psy & Korea & $\mathrm{PhD}$ \\
Sean & China & Master's \\
Sheila & Korea & $\mathrm{PhD}$ \\
\hline
\end{tabular}

\subsubsection{Trustworthiness}

Rigor was assured through the incorporation of procedures that address credibility, transferability, and dependability (Lincoln, 1995; Lincoln and Guba, 1985). Three techniques were utilized to address credibility (accuracy of information): (a) triangulation of data, (b) peer debriefing, and (c) member checking (Erlandson, Harris, Skipper and Allen, 1993; Lincoln and Guba, 1985). These added to the study's confirmability. The data was triangulated by gathering information from multiple sources (Master's and $\mathrm{PhD}$ students; students from China, Korea, Japan, and Taiwan). Two doctoral students from India and Korea from two other departments served as peer debriefers. As international students, they were able to relate to the topic of the study and provide key insights into which themes 
and concepts were most relevant to the analysis. Member checking was used (a) at the end of each interview, and with one participant, b) during the analysis and, c) at the end of data analysis. The latter two types of member checks were done through oral description of transcriptions to avoid compromising the participants' identity.

\subsection{Data Analysis}

Open, axial, and selective coding (Strauss and Corbin, 1998) were used to analyze the data. During open and axial coding, each transcript and field notes were analyzed, categories and sub-categories identified using the iterative process of "constant comparison," and connections made between the categories and sub-categories based on the causal conditions that give rise to them; the context in which they were embedded, actions or interactional strategies by which they were carried out, and the consequences of those strategies (Strauss and Corbin, 1990). These stages gave rise to 22 categories. In line with Strauss and Corbin $(1990,1998)$ the frequently-occurring core category was identified and systematically related to the other categories during selective coding so that a "story line" emerged that described the sources of the adjustment problems for the East Asian international graduate students in my sample. For this study, academic confidence emerged as the core category.

\section{Findings}

The main research question guiding this inquiry was: Why do East Asian international graduate students experience problems adjusting to academic life in the United States? The reflections of the study's participants indicated they first experienced lowered academic confidence which resulted in acculturative stress. Academic confidence was defined by the researcher during coding in terms of "whether the student described self as confident in their academics or as a 'good' student on campus." Occurring within the context of inside and outside of the students' department, the causal conditions influencing their lowered academic confidence were the challenges experienced during the first year of graduate school, limited language proficiency, the different teaching style and teaching environment in the USA, and perceptions of differential treatment, engagement, and grading by professors, and professors' lack of awareness and interest in international issues. Reduced student-faculty interaction (in the form of limited to zero in-class participation and out-of-class professors' office visits) and student drop-out were the actions through which the students' lowered academic confidence manifested themselves. Acculturative stress was the resulting consequence. Acculturative stress arises from difficulties associated with, which can manifest in various physical, social, and psychological problems (Nwadiora and McAdoo, 1996; Sandhu and Asrabadi, 1994). Berry, Kim, Minde and Mok (1987) associate acculturative stress with an individual's cross-cultural encounters. The acculturation may result in the individual undergoing five partly overlapping changes - physical changes, biological changes, cultural changes, new sets of social relationships, and psychological changes. The participants' narratives (their voices) tell the story of this theory.

\subsection{The Challenges of the First Year of Graduate School}

The First Year appeared to be the most daunting in the adjustment process for the seven international students. There were simultaneous academic, cultural, and social challenges to be overcome to the extent that none of the participants reported significant academic success in this year. For all seven participants their academic confidence was negatively affected by the difficulty of finding a balance between academic and settling-in issues. Psy admitted that it was her first experience studying in a foreign country. She said that she was "... not accustomed to the life in the USA, and the culture, systems, I did not have any idea about that" and that it was "hard to handle real life and academic life."

Reading requirements for their Year I classes was time-consuming. Sean noted that:

First year was very tough for me I mean because of language, I was not good in English so in the class it was really intense. Basically most time I don't understand what they are talking about in class, the discussion, so I can't follow the thought at all. That was really a challenge to me.

Psy remarked that although she was used to the large reading and writing requirements of Korean universities "I think it took 3 times time and effort but the results not as good as results in Korea." She was easily frustrated and had to "control myself to survive here."

The initial settling-in period proved challenging especially having to deal with the poor public transportation system and the shortage of Asian groceries and restaurants in [university town]. The Korean participants in particular had to adjust to differing expectations and requirements. According to Psy, "in Korea it is common to deliver a heavy product for free but here you have to pay for it." She said that "I didn't know about the check, checkbook. We didn't have that in Korea. I need to figure out by myself what is the checkbook." 
Adapting to a different culture was challenging. Sheila admitted that she had fallen for the stereotypes by which Americans are portrayed in her country. She said:

It was tough. I had this big dream that everyone becomes friends, that everyone has a party all the time. And I had some stereotypes about American people like you see on TV. That you can say anything to anyone. You can do anything you like. But totally different. It's much more conservative than I thought. ... I feel more constrained.

All of the participants observed that their expectations before coming to the USA were quite different from what they encountered on arrival. However, only two students indicated that they had experienced discrimination in [university town]. Sheila commented that she often felt discriminated against while shopping in the grocery store. She said that the store assistants would "throw products to me or talk sweet and friendly to the white person in front of me but when it's my turn they never say hi." Peter is Japanese and more than once had someone in a store or car, shout to him "go back to China". He attributed it to "maybe they have some hatred for Chinese." His experience also included "Often Americans make a frown face because of my English. They don't try to understand what we're saying."

Despite their adjustment problems in the first year, only two participants viewed dropping-out as an option during that year. Most sought to persist because as Anna put it: "Dropout is too terrible a situation. I would stand anything not to drop out." Lydia and Sheila were the two students who considered dropping-out in year one. The psychological experiences that Day and Hajj (1986) describe were a reality for them. According to Lydia, considering dropping-out was influenced by stress and the fact that the course turned out to be different to what she wanted to study.

Two of the seven participants sought the services of the on-campus Psychological and Counseling Center for help with their feelings of loneliness and alienation. Although one student [pseudonym and program of study with-held] said that in her first year she would not have dropped-out under any circumstances, she withdrew from the program during the course of this study. She returned to her country within a month of the interview. For the seven East Asian students, their academic confidence was lowered during the first year of their life on campus and in the new city due to required academic, linguistic, cultural and social adjustments.

\subsection{Language Proficiency}

The students' academic confidence was dented by their limited language proficiency. All seven participants in this study were non-native English speakers. While they chose to study in the USA, their relatively lower levels of English language proficiency guaranteed tremendous difficulties in the classroom. According to Sean, “...language is the first step to communicate. If you can't, I mean if you can't stand on the first step, then you can't go beyond your role."

This language barrier was a source of anguish for these students who viewed it as isolating and negatively affecting them at [the university]. For Lydia,

.... and because I'm not a native speaker it takes me more time to read, more time to understand, more time to write. And also a lot of time to prepare for presentations. Like I have to practice several times. The process is very slow. So I feel like I'm kinda behind other people.

The flow of topics covered in class would get too fast for Paul and he would get lost. More significantly, limited English proficiency impeded classroom participation and social involvement. For instance, it made both Sheila and Peter insecure about expressing themselves either in class or socially. For Sheila:

I cannot discuss freely about class materials or my research - I have a lot of questions or thoughts in class but I'm really afraid to say in public because perhaps my professors doesn't understand me, my classmates not understand me.

Peter commented that he was:

...still hesitant to talk to Americans for daily conversations. If they talk about what I know, it is fine but if they talk about something that I don't know, it is really very hard to, you know, follow. One characteristic of Americans is that they don't really care whether foreigners understand English. They take it for granted that we understand it. So, then you know, if I don't respond to them they think that I'm not listening. So you know being a non-native English speaker makes me out of place when I'm with Americans. 
The language barrier was only one aspect of the inability of these international students to participate in a US classroom. This study found silent classroom engagement became one of the most visible manifestations of the lowered academic confidence experienced by the seven study participants.

\subsection{Different Teaching Styles and Teaching Environments}

Lowered academic confidence also derived from differences between the teaching styles and environments of the students' home countries and that of the USA. In particular, all participants were conscious of the difference between the level of classroom participation between international students and American students. They characterized American students as very participatory. Peter described the typical classroom situation:

Americans they first speak, they first talk although they don't know what they're going to talk about. They have that tendency. So international students lose the opportunity to talk. For them, including me, we have we have to think about what we're going to talk first. Otherwise we won't make ourselves understand.

Levels of classroom participation differed by nationality because the teaching style and teaching environment in participants' countries of origin differed significantly from that in the USA. The lecture was the dominant teaching style in the countries from which the participants originated, with there being little or no in-class discussions. Class sizes could range from 30-500. Lydia informed that in Korea,

We have lots of lectures and very few students are asking questions. Students are sitting here. The teacher is standing up front there. He does the talking all the time. We are just sitting, listening. We never talk in class to teachers. If you have a question you may wait for the class to end. There's almost no class discussions. It's not really common, at all.

The same pattern was observed in China, Taiwan and Japan. According to Sheila, "as an Asian student I'm not trained to speak up in class."

However, Sean and Peter did manage to participate in class. Of the seven participants, Sean and Peter were observed to be the more social. Sean, for instance, stated that:

Here, personally I like the classroom participation a lot. I like the presentation very, very much. I do like standing in the classroom show my stuff, lead the discussions. My classmates listen to me, I feel very good.

The other five participants found it difficult to participate because they could not interrupt an on-going discussion. According to Psy,

If the professor gave me a chance or time, oh it's your turn can you talk about your opinion something, I can tell about something but I can't participate abruptly right? jump in the conversation. So it's very hard for me.

She said that in Korea students wait for their turn. Peter also commented on the difficulties of "jumping in", which was compounded by the time required formulate their questions or comments in English:

We need to have some time to talk with the right phrases. But while thinking Americans keep talking. It's very difficult for us to break in their continuous discussion.

The study participants also related their limited classroom participation to differing language structure. According to Lydia, the Korean language structure is opposite to that of English. She stated that:

Like something they say first, we say last, and something they say last we say first. So it's like totally the opposite. That's why participation is harder. We have to think through the whole sentence first and then translate.

The link between academic confidence and acculturative stress for these students was strengthened by the weight professors gave to classroom participation when calculating the course grade. Psy was of the opinion that US professors disadvantaged international students. She said that:

It's very subjective and arbitrary evaluation right? They just remember students [who] talk a lot, no matter it make sense or not but I just want to just make a contribution and to talk about very important things.

Psy stated that because she could not speak a lot in class, it gave professors the impression that she was an inactive student. Paul noted that this view was also shared by American students in the class. He commented that since it was recognized that he does not participate in class, his classmates ignored him when they engaged in small group discussions. Sometimes they took "care of him" and did not "force him" to speak. The effect on their academic 
confidence of the disparity in teaching styles and environments was evident in the tendency for most of study participants to remain silent within the American classroom.

\subsection{Interactions with Professors}

Academic confidence was set back by the nature of interactions between these international students and their professors and whether they perceived professors to be interested in international issues and the international diversity in their classrooms. Master's and $\mathrm{PhD}$ students differed on their perceptions about faculty members within and outside of the department. Interaction with professors within the department boosted the academic confidence of the Master's students while interaction with professors from other departments had the opposite effect on their confidence. The Master's students found their [master's program] professors to be interested in their international experience. Sean said that "I mean they encourage you to share your thoughts for your country or any other country other than US." Anna also endorsed this. These perceptions were not surprising given that Anna and Paul were two of the three Master's students enrolled in an international program. Anna suggested that the nature of the program contributed to professors' respect for the opinions of international students in her classes. She viewed the classroom as more inclusive when they discussed international issues:

I feel the professors in especially [master's program] courses focus on international issues, are more willing to involve international students - they push you to be involved. Professors will be looking at you like looking at you - say something, what your opinion about that. They really respect your opinions and value your opinions.

On the other hand, the three Master's students felt alienated in classes they took in other departments because international issues were not discussed and professors in those departments were not interested in international affairs or their experiences. Sean said this of one professor in particular,

I think the professor thinks your international story is interesting but for her, she doesn't have many like knowledge of international education setting so I don't think she really understand my points. And doesn't have much interest in digging behind the story to understand the theory.

This reaction caused him to feel "less encouraged." Anna's summarized her experience with professors outside of the department:

... if you don't speak, they won't, like why bother, pushing you to speak. They don't really want your opinion. They really don't want specifically your opinion and they don't really want specifically your opinion as an international student.

She said that classes she had taken outside the department were not inclusive:

...totally US-based. In the first class, it was a shock. She talked all the things about the US-[her field] system. They don't really care if it is an international student. I don't think that my experiences are undermined but I do think they are too inclusive.

The experience for PhD students was quite different from that of Masters' students. All four PhD students were of the opinion that it was only when they took a course outside of the department that they obtained good grades and were treated fairly. All four students believed that professors within their own department treated them differently from American students. They observed that their professors disengaged themselves from international students and their concerns.

Psy was of the opinion that professors in her department were prejudiced against international students. She commented that "they have a kind of prejudice about international students because of our writing or speaking." This frustrated her. Psy viewed her professors as focused only on American students and on those that were excellent students. They applied two different standards to work done by American and international students. For instance, Sheila recounted a situation from her first semester:

My first semester, one professor gave me and an American student an A-minus. On my paper, she said that I was well-prepared student, I am happy to have you. On his paper she wrote that she's was so disappointed with him, he could do better than this.

Regarding going to professors' offices during office hours, none of the participants in the study would go to professors' office hours to discuss grades. They were not confident to do this for cultural reasons and the perceived prejudice of professors. Similar to Wang's (2003) notion of "far' power, Sean related it to the status a professor holds in Chinese society: 
In China, the relationship between teacher and students is very serious. Like I would say kind of hierarchy. In traditional China, students are always obey the order of the teacher. I don't feel like comfortable to go to office and discuss. I have never talked about the grade to them.

For Psy, it was related to "losing face." Going to discuss grades would make professors to think that she was "very bad at my subject." She said that she tried to "do better myself rather than asking their help." Lydia did not think going to discuss grades would make a difference because of the professors' prejudice:

About the grading of the professors I think some of them have prejudice about non-native speakers. I think even before they look at our paper they already know we're non-native speaker. Even though I went to writing studio, they already say go to the writing studio and get it corrected. But that's have already been corrected from writing studio. So in that regard some have prejudice.

Besides to discuss grades, all four participants had reservations about going to professors' office hours generally. For Sheila and Peter, whether they went to office hours depended on the professor and their attitude towards them. Sheila said that: "If professors usually avoid talking to me, I don't feel comfortable going there." On the other hand, Lydia linked her reticence to language proficiency:

... I'm not very often prepared to go to office hours because in order to ask questions I have to study first. It takes me a lot of time to study first and to make the questions.

During his interview, Peter first professed that few professors in his department actually cared about international students. He then corrected himself to say: "Actually just one!" Most participants commented that there was only one professor in their department who was interested to provide assistance with regards to their adjustment to campus life. With regard to the other professors, Sean felt that they don't do enough while Peter said: "They don't care". Psy suggested that other professors did not know "specific ways to help". The perception of disengaged professors affected students' academic self-confidence and contributed to their acculturative stress.

\section{Discussion and Conclusions}

This study sought to identify why academic adjustment problems occurs from the experiences of a sample of seven East Asian international students pursuing graduate studies at an elite US private not-for-profit doctoral university in the highest research activity category. Cross-cultural research suggests that international students from collectivist cultural backgrounds may experience lower levels of life satisfaction and higher levels of anxiety than international students from individualist cultures (Wang, 2011).

Interview data analyzed using a grounded theory methodology reveal that as the East Asian international graduate students adjusted to life in the USA, lowered academic confidence precipitated experiences of acculturative stress. The students' narratives suggest that their confidence was negatively impacted as early as the first year of graduate school. The students had to balance adjustment to a new culture with academic life and its heavy reading requirements. Low language proficiency limited reading gains, affected settling-in, and made them hesitant to engage with professors and other students in- and out-side the classroom. Their level of classroom participation became limited to non-existent, shaped as it was by their familiarity and prolonged exposure to the teacher-centered lecture methods in their home countries. The large weight professors gave to classroom participation in the course grade added to the stress experienced.

Perceptions about the treatment and engagement fostered by faculty members within and outside of the department differed depending on whether the participants were enrolled in a Master's or PhD program. Master's students' acculturative stress related to their perceptions that professors outside of their department lacked awareness of and interest in international issues. In contrast, the stress experienced by $\mathrm{PhD}$ students related to their perceptions that faculty members within their own department treated and graded them differently from American students, and lacked interest in international issues generally, and in international students and their specific adjustment problems. Reduced student-faculty interaction (in the form of diminished in-class participation and out-of-class visits to professors' offices) and student drop-out (for one student) were some of the actions through which the students' lowered academic confidence manifested themselves. Acculturative stress was the resulting consequence.

International students have positive economic and educational impacts on their US host country. However, from the narratives of the East Asian graduate students in this study, adjustment to the new culture is not smooth and results in acculturative stress. One conclusion that can be drawn from study participants' experiences is that while it may be expected that cultural differences impact international students' academic and social integration at the institutional-level, significant negative effects may exist at a department-level. This cultural effect suggests colleges and universities adopt micro-level strategies (e.g. faculty and staff workshops or seminars) to raise the sensitivity of 
departmental academic and administrative staff to the cultural differences and problems of international students originating from the same region and different regions.

A second conclusion is that once ingrained in the campus environment, acculturative stress does not necessarily disappear with time spent in the host country or in an academic program. The $\mathrm{PhD}$ students share similar experiences despite being in their second, third and fifth years implying that the psychological, social, and physical effects of transitioning to a new culture persisted for students enrolled in a five-year program. Persisting stress levels suggest early interventions. The usual provision of an orientation session for international students in the first year may not be sufficient for students originating from the East Asia region. Additional information-sharing on American and local culture are required to encourage success among these students. It may also be imperative for international student services and/or student affairs units to slot in early individual assessment appointments with staff at the psychological and counseling center for East Asian graduate students on their arrival to campus or during orientation week.

A third conclusion is that within a department, academic confidence is not necessarily higher among international East Asian PhD students as a group as compared to international East Asian Master's students. There is a differential effect at the student-level of the causal conditions identified in the narratives. Individual students' language proficiency, in particular, accounts for the varied levels of academic confidence. The narratives suggest increased conversation classes are important and that as a source of on-campus support for $\mathrm{PhD}$ international students, the program offered by campus' writing center is too basic for their needs. Of more relevance is the students' recommendation for a department-provided writing counselor to help them meet the department's writing style requirements.

The acculturative stress experienced at the department-level by the $\mathrm{PhD}$ students was overwhelmingly negative. However, apart from faculty members' limited cultural sensitivity, it is not clear from transcript data whether their experiences were also shaped by (1) the general expectation of faculty members that $\mathrm{PhD}$ students ought to be more independent and demonstrate self-efficacy, or (2) the high-intensity research activity of faculty members which might have rendered them more "clinical" than humanistic. Faculty members exercise autonomy regarding pursuing their research interest vis-à-vis teaching (Braxton and Bayer, 1999). The discretion they exercise regarding these professional choices may affect their time, ability, and willingness to engage international students. Given that East Asian countries account for four of the top ten countries sending students to the USA, instances of acculturative stress experienced by students originating from these countries require deeper explanation. Future research is warranted that explores the perceptions of faculty members regarding the in-class performance of East Asian graduate students, and their own levels of cultural awareness and engagement with these students both in and outside of class.

The Master's students in the study had a more favorable within-department experience. It is not clear from transcript data whether their experiences were due to (1) the fact that their program was an international program and hence their classroom discussions necessarily centered around international issues, (2) the fact that the research interests of their professors was international issues hence their interest in their foreign students' opinions, or (3) their professors treated the Master's students better because they were paying clients. A definitive explanation for the differing perceptions between Master's and $\mathrm{PhD}$ about faculty is not apparent; what is clear is that the different perceptions are real.

A final conclusion that can be drawn from study participants' experiences is that institutional programming and services need to be intensified for international student sub-populations. Although the data was obtained for a sample of East Asian international graduate students in a single department, these findings have implications for the future recruitment of East Asian international students generally. At an institutional level, campus support offices need to be cognizant of findings in the research literature and be more effective in their outreach to these students. Obtaining regular feedback from these students will also help colleges and universities better serve its international clients and reduce the incidence of acculturative stress. Feedback might be obtained through online surveys or scheduled feedback sessions with students. Communication is definitely key to addressing the problems faced by international students as they adjust to student life in the USA.

\section{References}

Al-Sharideh, K., \& Goe, W.R. (1998). Ethnic communities within the university: An examination of factors influencing the personal adjustment of international students. Research in Higher Education, 39(6), 699-725. https://doi.org/10.1023/A:1018714125581

Athen, G. (1991). Some help and some myths. The Counseling Psychologist, 19, 62-65. https://doi.org/10.1177/0011000091191004 
Barratt, M. F. \& Huba, M. E. (1994). Factors related to international undergraduate student adjustment in an American community. College Student Journal, 28, 422-435.

Berry, J. W., Kim, U., Minde, T., and Mok, D. (1987). Comparative studies of acculturative stress. The International Migration Review, 21(3), 491-511. https://doi.org/10.2307/2546607

Boyer, S. P. \& Sedlacek, W. E. (1988). Noncognitive predictors of academic success for international students: A longitudinal study. Journal of College Student Development, 29(3), 218-223.

Braxton, J. M., \& Bayer, A. E. (1999). Faculty misconduct in collegiate teaching. Baltimore, Md.: Johns Hopkins University Press.

Charmaz, K. (2000). Grounded theory: Objectivist and constructivist methods. In N. Denzin \& Y. S. Lincoln (Eds.), Handbook of Qualitative Research (2nd ed. pp. 509-536). Thousand Oaks, CA: Sage.

Cigularova, D. K. (2005). Psychosocial adjustment of international students. Journal of Student Affairs, 14, 1-16.

De Araujo, A. A. (2011). Adjustment issues of international students enrolled in American colleges and universities: A review of the literature. Higher Education Studies, 1(1), 2-8. https://doi.org/10.5539/hes.v1n1p2

Day, R. \& Hajj, F. (1986). Delivering counseling services to international students: The experience of the American University of Beirut. Journal of College Student Personnel, 27. 353-357.

Erlandson, D. A., Harris, E. L., Skipper, B. L., \& Allen, S. D. (1993). Doing naturalistic research. A guide to methods. Newbury Park, CA: Sage.

Goodman, A. E. (1996). What foreign students contribute? The Chronicle of Higher Education, February 16, 1996.

Hechanova-Alampay, R., Beehr, T. A., Christiansen, N. D., \& Horn, R. K. V. (2002). Adjustment and strain among domestic and international student sojourners: A longitudinal study. School Psychology International, 23(4), 458-474. https://doi.org/10.1177/0143034302234007

Hofstede, G., \& Bond, M. (1984). Hofstede's cultural dimensions: An independent validation using Rokeach's values survey. Journal of Cross-Cultural Psychology, 15, 417-433. https://doi.org/10.1177/0022002184015004003

Institute of International Education (2016). Open doors 2015: Report on International Educational Exchange. Washington, DC: Institute of International Education.

Kuh, G. D., Kinzie, J., Schuh, J. H., Whitt, E. J., \& Associates (2010). Student success in college; creating conditions that matter. San Francisco, CA: Jossey-Bass.

Leong, F. T. L. \& Sedlacek, W. E. (1989). Academic and career needs of international and United States college students. Journal of College Student Development, 30, 106-111.

Lin, J. \& Yi, J. K. (1997). Asian international students' adjustment: Issues and program suggestions. College Student Journal, 31, 473-479.

Lincoln, Y. S. (1995, April). Emerging criteria for quality in qualitative and interpretive research. Keynote address presented at the annual meeting of the American Educational Research Association, San Francisco, CA. https://doi.org/10.1177/107780049500100301

Lincoln, Y. S., \& Guba, E. G. (1985). Naturalistic inquiry. Beverly Hills, CA: Sage.

Mori, S. (2000). Addressing the mental health concerns of international students. Journal of Counseling \& Development, 78, 137-144. https://doi.org/10.1002/j.1556-6676.2000.tb02571.x

Pedersen, P. B. (1991). Counseling international students. The Counseling Psychologist, 19(1), 10-58. https://doi.org/10.1177/0011000091191002

Perkins, C.S., Perkins, M.L., Guglielmino, L.M., \& Reiff, R. F. (1977). A comparison of the adjustment problems of three international student groups. Journal of College Student Personnel, 18(5), 382-388.

Poyrazli, S. \& Grahame, K. M. (2007). Barriers to adjustment: needs of international students within a semi-urban campus community. Journal of Instructional Psychology, 34, 1.

Redmond, M. V., \& Bunyi, J. M. (1993). The relationship of intercultural communication competence with stress and the handling of stress as reported by international students. International Journal of Intercultural Relations, 17, 235-254. https://doi.org/10.1016/0147-1767(93)90027-6 
Rubin, H. J., \& Rubin, I. S. (1995). Qualitative interviewing: The art of hearing data. Thousand Oaks, CA: Sage.

Sam, D. L. (2001). Satisfaction with life among international students: An exploratory study. Social Indicators Research, 53, 315-337. https://doi.org/10.1023/A:1007108614571

Sandhu, D. S., \& Asrabadi, B. R. (1994). Development of an acculturative stress scale for international students: Preliminary findings. Psychological Reports, 75, 435-448. https://doi.org/10.2466/pr0.1994.75.1.435

Strauss, A., \& Corbin, J. (1990). Basics of qualitative research. Grounded theory procedures and techniques. Newbury Park, CA: Sage.

Strauss, A., \& Corbin, J. (1998). Basics of qualitative research: Techniques and procedures for developing grounded theory (2nd ed.). Thousand Oaks, CA: Sage

Surdam, J. C. \& Collins, J. R. (1984). Adaptation of international students: A cause for concern. Journal of College Student Personnel, 25, 240-245.

Swagler, M. \& Ellis, M. (2003). Crossing the distance: Adjustment of Taiwanese students in the United States. Journal of Counseling Psychology, 50, 420-457. https://doi.org/10.1037/0022-0167.50.4.420

Van Oudenhoven, J. P. \& Van der Zeek, K. (2002). Predicting multicultural effectiveness of international students: The Multicultural Personality Questionnaire. International Journal of Intercultural Relations, 26, 679-694. https://doi.org/10.1016/S0147-1767(02)00041-X

Wan, T., Chapman, D. W., \& Biggs, D. A. (1992). Academic stress of international students attending U.S. university. Research in Higher Education, 33(5), 607-622. https://doi.org/10.1007/BF00973761

Wang, J. (2003). A study of the adjustment of international graduate students at American universities, including both resilience characteristics and traditional background factors. Electronic Theses, Treatises and Dissertations. Paper 1270. http://diginole.lib.fsu.edu/etd/1270

Wang, M. (2011). Adjustment challenges for East Asian International Students. Master's Thesis. New York: State

White, A., Brown, S., \& Suddick, D. (1983). Academic factors affecting the scholastic performance of international students. College Student Journal, 17, 268-272.

Wilton, L. \& Constantine, M. G. (2003). Length of residence, cultural adjustment differences, and psychological distress symptoms in Asian and Lain-American international college students. Journal of College Counseling, 6, 172-186. https://doi.org/10.1002/j.2161-1882.2003.tb00238.x

Winkler, D. R. (1984). The costs and benefits of foreign students in United States higher education. Journal of Public Policy, 4(2), 115-138. https://doi.org/10.1017/S0143814X00002099

Yang, B., \& Clum, G. A. (1994). Life stress, social support, and problem-solving skills predictive of depressive symptoms, hopelessness, and suicide ideation in an Asian student population: A test of a model. Suicide \& Life-Threatening Behavior, 24(2), 127-139.

Yeh, C. J. \& Inose, M. (2003). International students' reported English fluency, social support satisfaction, and social connectedness as predictors of acculturative stress. Counseling Psychology Quarterly, 16(1), 15-28. https://doi.org/10.1080/0951507031000114058

Yuan, W. (2010). Investigating international student perceptions of adjustment through Q methodology. Intercultural Communication Studies, 19(2), 235-252.

Zhai, L. (2004). Studying international students: Adjustment issues and social support. Journal of International Agricultural and Extension Education, 11(1), 97-104. https://doi.org/10.5191/jiaee.2004.11111 